\title{
Smart Specialisation Strategy (S3) and Social Network Analysis (SNA): Mapping Capabilities in Calabria
}

\author{
Arnault Morisson $^{1,2(\triangle)}\left(\mathbb{D}\right.$, Carmelina Bevilacqua $^{1}$ (D), \\ and Mathieu Doussineau ${ }^{3}$ (D) \\ ${ }^{1}$ Mediterranean University of Reggio Calabria, Reggio Calabria, Italy \\ arnault.morisson@unirc.it \\ 2 Utrecht University, Utrecht, The Netherlands \\ ${ }^{3}$ European Commission, Joint Research Centre Seville, Seville, Spain
}

\begin{abstract}
The concept of smart specialization strategy (S3) requires regions to have an extended knowledge of their institutional contexts in order for policymakers to design the most adapted place-based innovation policies. In the context of the next programming period of EU Cohesion Policy 2021-2027, this paper explores the use of social network analysis (SNA) in mapping regional capabilities in Calabria. Using the CORDIS database, the paper finds that SNA can inform policymakers on key aspects of the enabling conditions for smart specialization such as governance, the entrepreneurial discovery process (EDP), priority setting, and interregional collaboration.
\end{abstract}

Keywords: Entrepreneurial discovery process - Interregional collaboration · Peripheral region $\cdot$ Horizon $2020 \cdot$ Governance

\section{Introduction}

In the European Union (EU), the future programming period of EU Cohesion Policy 2021-2027 dedicates a substantial share of its budget to promoting a Smarter Europe through, notably, the confirmation of the Smart Specialisation Strategy concept (S3) after a first experiment during the 2014-2020 programming period [1]. S3 is a policy concept to support regional prioritization in innovative sectors, fields or technologies through the entrepreneurial discovery process (EDP), a bottom-up approach to reveal what a region does best in terms of its scientific and technological endowments [2].

In the S3 implementation, the European Commission (EC) and the European Parliament have pushed for synergies across EU funding, namely between the European Structural and Investment Funds (ESIF) and Horizon 2020 [3]. In the next programming period 2021-2027, synergies across EU funding are even more crucial to maximize investments in research and innovation at the regional scale.

Many regions have faced difficulties in designing and implementing their S3 in the programming period 2014-2020, most notably related to S3 governance, monitoring, 
and the entrepreneurial discovery process [4]. For the new programming period 20212027, the EC has requested national and regional authorities to update their S3 and respond to seven 'enabling conditions' under the new Cohesion Policy [5]. The European Commission encourages regions to use evidence-based approaches combined with a wide involvement of stakeholders coming from the quadruple helix-private sector, public institutions, universities, and civil society-to update their S3. Triple helix models of innovation involving the private sector, public institutions, and universities and increasingly quintuple models of innovation that incorporate the triple helix, civil society, and the environment are frequently used in S3 [6]. Depending on what helix is most appropriate at the regional institutional level to address regional challenges and priorities, regions must adopt an entrepreneurial discovery process (EDP), which is a bottom-up process involving a wide range of stakeholders to define regional actions and to identify regional technological opportunities.

S3 requires regions to have a comprehensive knowledge of their institutional contexts to design the most adapted place-based innovation policies [7]. This mapping exercise of scientific and technological capabilities is, however, often lacking. In southern Italy for instance, most southern Italian regions selected high-tech specialisation areas despite having little capacities in scientific and technological capacities [8]. The evolutionary economic geography (EEG) and regional innovation system (RIS) literatures have introduced tools to help policymakers to design innovation policies that are tailored to their regional institutional contexts. The RIS literature provides conceptual frameworks depending on the type of regions to support new industrial path development $[9,10]$. In EEG, the concept of economic relatedness offers a robust tool for regions to prioritise and select the most relevant regional sectors [11].

The JRC S3 platform and H2020 project 'S3 Online' have listed tools to support regional policymakers in drafting and updating their S3. Some examples of quantitative tools are related variety analysis, extroversion analysis, and so on. Some examples of qualitative tools are SWOT analysis, benchmarking, foresight exercises, regional assets mapping, and so on. Social network analysis (SNA) is, however, not highlighted as a relevant policy tool for S3.

This paper explores the use of SNA in mapping regional capabilities in Calabria and its potential application for regional policymakers in the context of updating their S3 for the next programming period 2021-2027. The research question that this paper aims to answer is: how SNA could be used to map regional scientific capabilities and interregional collaboration opportunities to support the S3? The authors selected Calabria as it is a peripheral region in South Italy. In the regional innovation scoreboard, the region is defined as moderate- and is ranked 203 out of 238 regions in Europe [12]. Calabria has a gross domestic product (GDP) PPS per capita of $€ 17,400$ in 2017, compared with $€ 28,900$ in Italy and $€ 30,000$ in the European Union [13]. For the programming period 2014-2020, Calabria selected to prioritize for its S3 the following sectors: sustainable construction, healthy living care services and products (life sciences), reducing environmental impacts and harm from natural hazards, ICTs and new 
technologies for tourism and cultural industries, developing the ICTs and innovative services sectors, providing healthy and safe food (agri-food), technologies for logistics, and advanced technologies and solutions for manufacturing [14].

The data come from the CORDIS database, which compiled data on all EU research projects under Horizon 2020 (2014-2020) [15]. H2020 research projects are used as a proxy to map regional scientific capabilities to be mobilized in the S3. However, this approach has limitations since it only maps regional scientific capabilities in H2020 research projects. The Calabria Region participated in $51 \mathrm{H} 2020$ research projects that have involved a total of 578 unique organizations. The paper finds that SNA can inform policymakers on key aspects of the enabling conditions for smart specialization such as governance, the entrepreneurial discovery process (EDP), priority setting, and interregional collaboration.

\section{Methodology}

This paper explores the use of social network analysis in mapping regional capabilities in Calabria and its potential application for regional policymakers in the context of updating their S3 for the next programming period 2021-2027. Social network analysis (SNA) is a research tool that has frequently been used to study European Framework Programs [16]. SNA is the study of the collection, management, analysis, interpretation, and presentation of relational data to analyze entire social structures (complete networks) or local networks (ego-centered networks) [17]. Our social network includes nodes (organizations or projects) and ties (interactions between the nodes) that connect them.

To build our networks, we use data coming from the CORDIS database, which compiled data on all EU research projects under Horizon 2020 (2014-2020) [15]. The CORDIS database of Horizon 2020 research projects offers many advantages for research purposes as it is well-structured and standardized. Moreover, Horizon 2020 is the biggest EU Research and Innovation program ever with nearly $€ 80$ billion of funding available over 7 years from 2014 to 2020 [18]. Other collaborative programs database could be used to map regional capabilities, such as EUREKA, Knowledge and Innovative Communities (KICs), or INTERREG. We only use the H2020 projects in which at least one organization from the Calabria region is present as a participant or coordinator. We consider the co-participation in the same H2020 projects as a tie within our network. We postulate that within the same $\mathrm{H} 2020$ project the organizations participating in the project are connected with one another. In total, 26 unique organizations from the Calabria region have participated in 51 different H2020 research projects, which involved a total of 578 unique organizations with 7438 ties.

Horizon 2020 research projects are used as a proxy to map regional scientific capabilities to be mobilized in the S3. To get funded, Horizon 2020 research projects are selected on a competitive basis. We thus assume that H2020 research projects 
represent the most competitive scientific knowledge in a region. However, this approach has limitations since it only maps regional scientific capabilities in H2020 research projects. To reduce these limitations, regional and national collaborative research projects and projects funded under thematic objective 1 "Research and Innovation" of the Calabria Operational Program 2014-2020 could be included in the SNA.

The authors use $R$ and different packages such as igraph, sna, EconGeo, ggplot2... to graph the network and to calculate different network centrality measures such as degree centrality (number of edges per node), betweenness centrality (nodes bridging position between other nodes), closeness centrality (distance between nodes), and eigenvector centrality (nodes connected to highly connected nodes) [19]. In our networks, betweenness centrality is particularly useful to identify the actors or projects acting as brokers or gatekeeper between actors or projects. Networks are built for the $\mathrm{H} 2020$ research projects and for the organizations participating in the H2020 research projects. The networks are undirected and not weighted.

\section{Findings}

\subsection{H2020 Research Projects Network in Calabria}

In looking at H2020 research projects, SNA can inform on the links between projects, their centralities in the network, and the type of competitive research programs in the region. Networks in Fig. 1 represent the network of H2020 research projects that involve at least a Calabrian organization. The types of programs are coded according to CORDA Data Dictionary [20]. The sizes of the nodes in the network on the left represent the research project total cost while the sizes of the nodes in the network on the right represent the projects' betweenness centrality score showing the projects acting as bridges among actors in the network. The network shows a large presence of programs related to research, namely Future and Emerging Technologies (FET) and Marie-Curie Sklodowska Actions. Compared to the priorities selected for its S3, Calabria has H2020 research projects related to climate actions, food and agriculture, and ICT that have high betweenness centrality scores and high budget confirming their relevance of the S3 priorities, namely TARANTO, E-SHAPE, or ERA-PLANET. The $\mathrm{H} 2020$ research project SuperScienceMe, a project to promote research and science, is coordinated by the University of Calabria and has the highest betweenness centrality score.

The implications for $\mathrm{S} 3$ of this network are to confirm the strategic regional importance of the $\mathrm{S} 3$ priorities, to highlight scientific capabilities in specific domains, and to underline central research projects. 


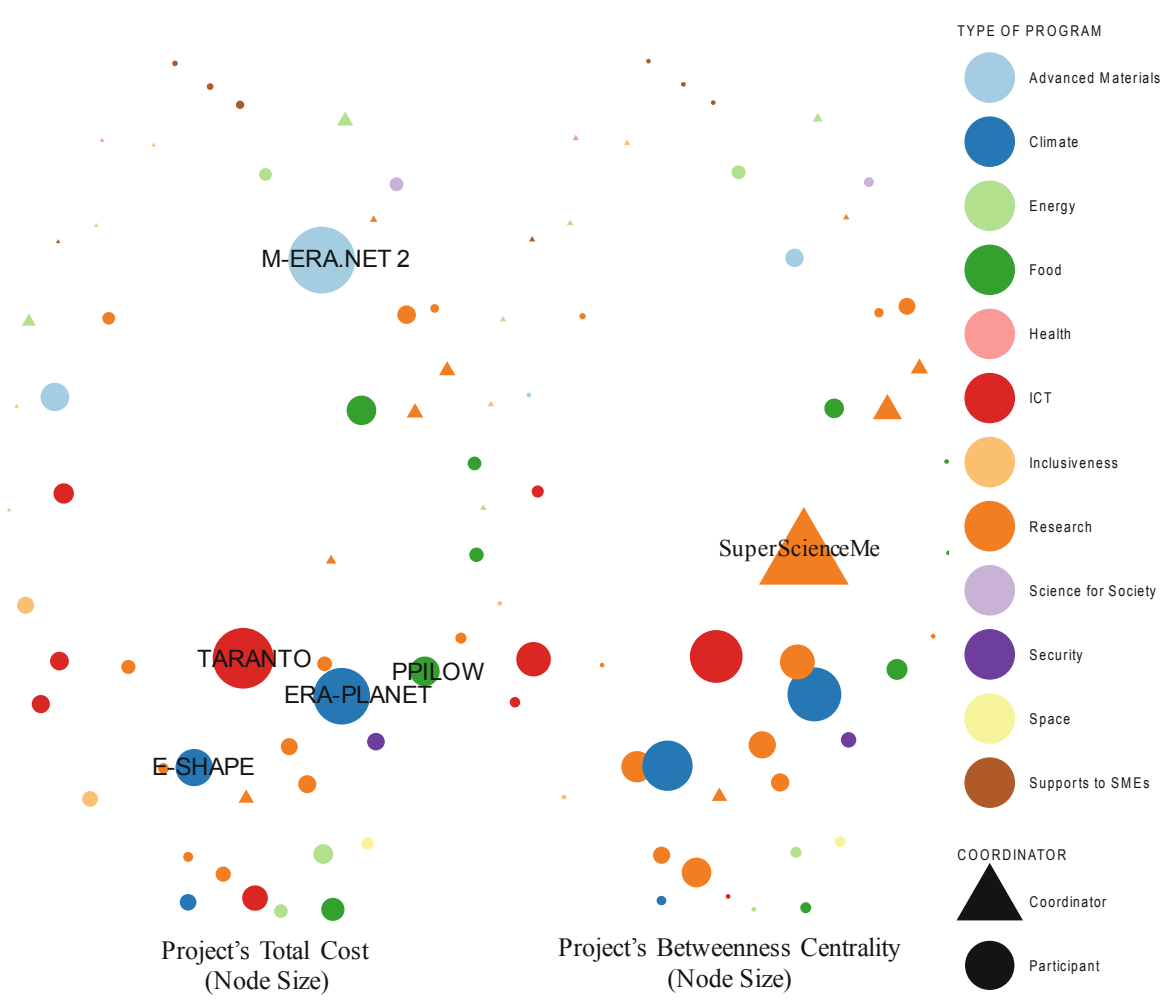

Fig. 1. Networks of H2020 projects in Calabria with their total costs (left) and betweenness centrality (right). Source: own design.

\subsection{Organizations in $\mathbf{H 2 0 2 0}$ Research Projects Network in Calabria}

In looking at organizations participating in $\mathrm{H} 2020$ research projects, SNA can inform on the links between organizations depending on different parameters such as locations or activities, their centralities in the network, and their positions in the network. Figure 2 represents the unique organizations that have participated in a $\mathrm{H} 2020$ research project in which a Calabrian organization is also present. The size of the node represents the betweenness centrality score, which allows to identify the organizations that might act as brokers or gatekeepers among different organizations in different research projects. As a result, the network underlines the key organizations in the network. It shows that Calabrian organizations are not well connected in the network with the exception of the University of Calabria, the Calabria Regional Council, the Mediterranean University of Reggio Calabria, and Bioage SRL. Many Italian organizations are well-connected with one another but not with the rest of the network. There is a large number of higher or secondary education establishments (HES) in the network. 
The implications for S3 of this network are to identify key organizations in the network, to identify extra-regional organizations that are central in the network that could potential work as brokers or gatekeepers, and to look at ties between regions and/or countries.

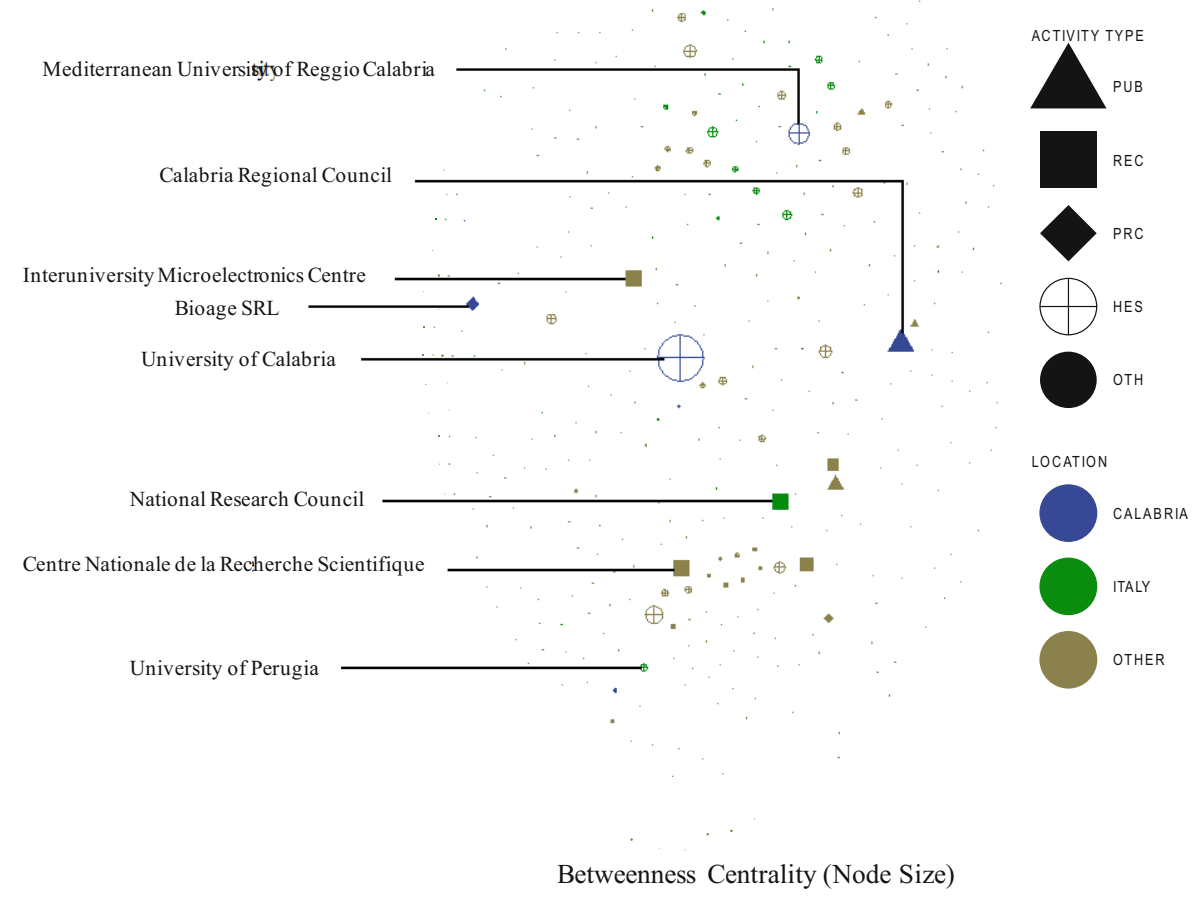

Fig. 2. Networks of organizations participating in H2020 projects in Calabria with their betweeness centrality. Public bodies (PUB), research organizations (REC), private for-profit entities (PRC), higher or secondary education establishments (HES), other (OTH). Source: own design.

Table 1 shows the five Calabrian organizations that are the most central in the network per network centrality measures (betweenness, closeness, eigenvector, and degree). The table shows the importance of universities and public organizations in the network. The only private company that is in the table is Bioage SRL, a high-tech private company. 
The implications for S3 of these network centrality measures are to identify the most central organizations in the network. In Calabria, the University of Calabria, the Calabria Regional Council, and the Mediterranean University of Reggio Calabria are the most central organizations. The network centrality measures facilitate the selection of key organizations that must be involved in the entrepreneurial discovery process (EDP).

Table 1. Most central Calabrian organizations in H2020 projects. Source: authors

\begin{tabular}{l|l|l|l|l}
\hline & $\begin{array}{l}\text { Betweenness } \\
\text { centrality }\end{array}$ & $\begin{array}{l}\text { Closeness } \\
\text { centrality }\end{array}$ & $\begin{array}{l}\text { Eigenvector } \\
\text { centrality }\end{array}$ & Degree centrality \\
\hline 1 & $\begin{array}{l}\text { Universita della } \\
\text { Calabria }\end{array}$ & $\begin{array}{l}\text { Universita della } \\
\text { Calabria }\end{array}$ & $\begin{array}{l}\text { Universita della } \\
\text { Calabria }\end{array}$ & Universita della Calabria \\
\hline 2 & $\begin{array}{l}\text { Universita degli } \\
\text { Studi } \\
\text { Mediterranea di } \\
\text { Reggio Calabria }\end{array}$ & $\begin{array}{l}\text { Universita degli } \\
\text { Studi Mediterranea } \\
\text { di Reggio Calabria }\end{array}$ & Calabria Region & Calabria Region \\
\hline 3 & Calabria Region & Calabria Region & $\begin{array}{l}\text { Consorzio per il } \\
\text { Lavoro le Attivita } \\
\text { Innovative e } \\
\text { Formative }\end{array}$ & $\begin{array}{l}\text { Universita degli Studi } \\
\text { Mediterranea di Reggio } \\
\text { Calabria }\end{array}$ \\
\hline 4 & Bioage SRL & $\begin{array}{l}\text { Universita degli } \\
\text { Studi Magna } \\
\text { Graecia di } \\
\text { Catanzaro }\end{array}$ & $\begin{array}{l}\text { Universita degli } \\
\text { Studi Mediterranea } \\
\text { di Reggio Calabria }\end{array}$ & $\begin{array}{l}\text { Associazione Italiana per } \\
\text { l'Agricoltura Biologica }\end{array}$ \\
\hline 5 & $\begin{array}{l}\text { Associazione } \\
\text { Italiana per } \\
\text { l'Agricoltura } \\
\text { Biologica }\end{array}$ & $\begin{array}{l}\text { Lavoro le Attivita } \\
\text { Innovative e } \\
\text { Formative }\end{array}$ & $\begin{array}{l}\text { Associazione } \\
\text { Italiana per } \\
\text { l'Agricoltura } \\
\text { Biologica }\end{array}$ & $\begin{array}{l}\text { Agenzia Locale per l'Energia } \\
\text { e lo Sviluppo Sostenible } \\
\text { della Provincia della } \\
\text { Provincia di Consenza SRL }\end{array}$ \\
\hline
\end{tabular}

\subsection{Interactions Across Technologies Within H2020 Research Projects in Calabria}

Interactions across technologies can inform policymakers on scientific relatedness across research topics. The Fig. 3 is a chord diagram that shows the interactions among the different $\mathrm{H} 2020$ research projects that are technology-related (from E.U.2.0 to E.U.3.7). An interaction between ICT and energy for instance, is created when an organization participating in a $\mathrm{H} 2020$ research project in ICT is also participating in a H2020 research project in energy. The Fig. 3 shows strong interactions between food and agriculture and climate action $\mathrm{H} 2020$ research projects and between energy and climate action $\mathrm{H} 2020$ research projects. 
The implications for S3 of this chord diagram are to identify the connections between the technologies and also to support the prioritization process.

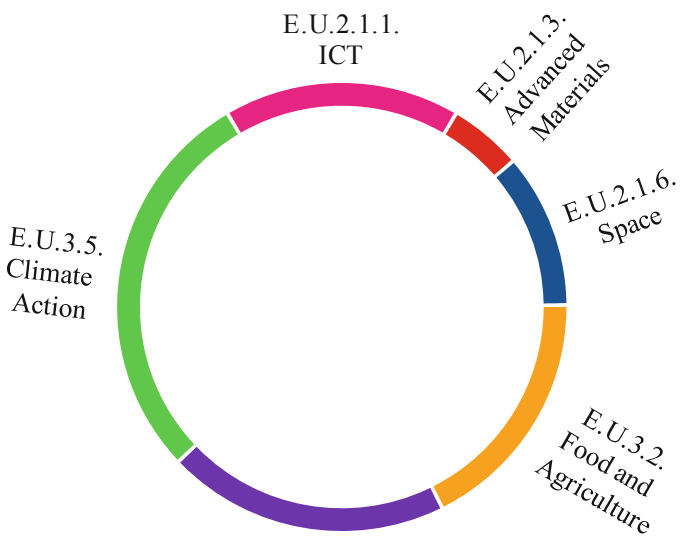

E.U.3.3.

Energy

Fig. 3. Interactions across technologies in H2020 research projects in Calabria. Source: own design.

\subsection{Interregional Collaboration in H2020 Research Projects in Calabria}

Mapping interregional collaboration informs policymakers on up-to-date regional scientific collaboration activities within the network. Figure 4 represents the number of organizations per city participating in a H2020 research projects in which a Calabrian organization is present. The map shows that Calabrian organizations are wellconnected with organizations located in Spanish cities, namely Madrid, Barcelona, Valencia, and Seville, and with organizations located in Paris, Brussels, and Vienna.

The implications for S3 of this map are to build-up on existing collaboration networks and identify cities and regions for interregional collaboration activities. 


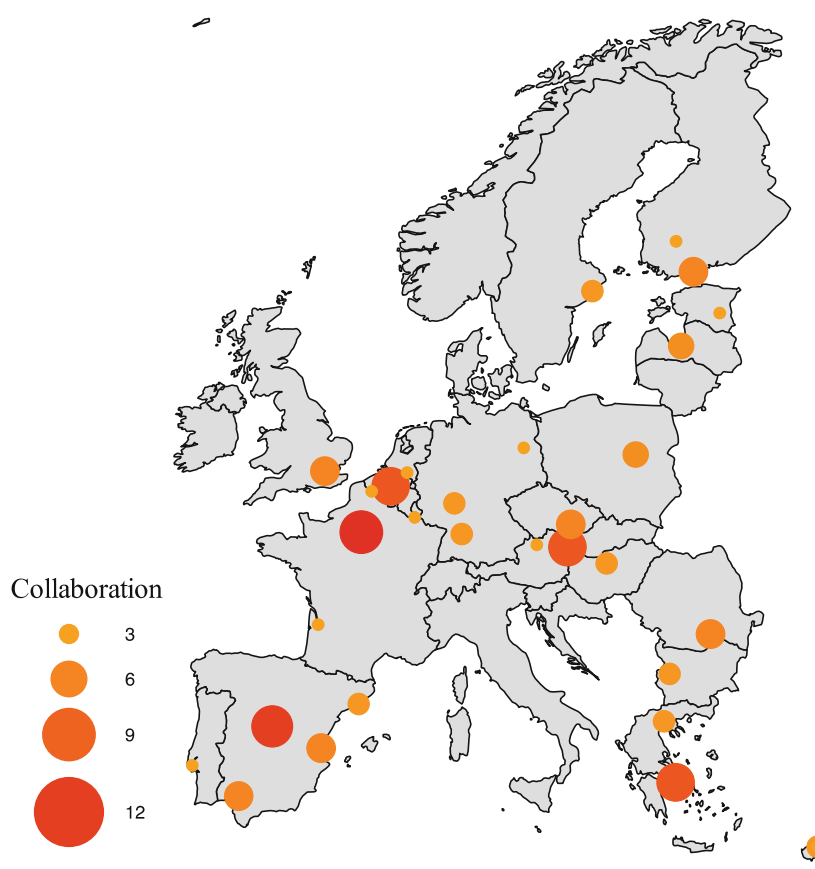

Fig. 4. Number of organizations outside of Italy collaborating with Calabrian organization in H2020 projects. Source: own design.

\section{Discussion and Conclusions}

Using CORDIS open database of H2020 research projects, social network analysis (SNA) offers some insights for updating smart specialisation strategy (S3) for the next programming period 2021-2027. For priority setting, it helps mapping existing scientific capabilities in $\mathrm{H} 2020$ research projects. Indeed, it can show strengths in scientific capacities such as in climate actions, food and agriculture, and ICT in the case of Calabria. For governance and the entrepreneurial discovery process (EDP), SNA supports the identification of key and well-connected organizations in the network as well as those working as bridges in the network. The identified organizations must play a role in the governance and in the EDP such as piloting working groups on prioritised sectors. The identification of actors is an important action to build an effective EDP, qualitative concepts embedded in places must rally actors together towards a common vision for the future [21]. For the interregional dimension, centrality network measures can support the identification of key and well-connected extra-regional organizations. Finally, a map can be produced to highlight existing collaboration and create interregional collaboration activities according to existing collaboration networks.

In Calabria, the network is characterized by the central role of public organizations and universities in the network and a weaker role of private companies. The SNA confirms the weak role of private actors in the RIS of peripheral regions [9]. One potential path to strengthen the network is to always involve a private company with a 
university in $\mathrm{H} 2020$ research projects thus allowing private companies to have access through a better connected actor, such as the University of Calabria or Mediterranean University of Reggio Calabria, to a larger number of ties in the network. Future research could use SNA for H2020 research projects and other collaborative research projects in different institutional contexts.

Acknowledgments. This research is part of the TREnD project (Transition with Resilience for Evolutionary Development), which has received funding from the European Union's Horizon 2020 research and innovation program under the Marie Skłodowska-Curie grant agreement No. 823952 .

\section{References}

1. European Commission, New Cohesion Policy, http://ec.europa.eu/regional_policy/en/2021_ 2027/. Accessed 19 Dec 2019

2. Foray, D., David, P., Hall, B.H.: Smart Specialisation - The Concept. Knowledge Economists. Policy Brief Number 9, June. European Commission, DG research, Brussels (2009)

3. Doussineau, M., Arregui-Pabollet, E., Harrap, N., Merida, F.: Stairway to Excellence: Drawing Funding and Financing Scenarios for Effective Implementation of Smart Specialisation Strategies. Joint Research Centre, Seville (2018)

4. Guzzo, F., Gianelle, C., Marinelli, E.: Smart Specialisation at Work: The Policy Makers' View on Strategy Design and Implementation. Joint Research Centre, Seville (2018)

5. European Commission: Regulation of the European Parliament and of the Council. European Commission, Brussels (2019)

6. Carayannis, E.G., Rakhmatullin, R.: The quadruple/quintuple innovation helixes and smart specialisation strategies for sustainable and inclusive growth in Europe and beyond. J. Knowl. Econ. 5(2), 212-239 (2014)

7. Morisson, A., Doussineau, M.: Regional innovation governance and place-based policies: design, implementation and implications. Reg. Stud. Reg. Sci. 6(1), 101-116 (2019)

8. Caramis, A., Lucianetti, L.F.: Scoperta imprenditoriale e strategie di specializzazione intelligente: dalla teoria alla pratica. Sci. Reg. - Ital. J. Reg. Sci. 15(3), 67-84 (2016)

9. Trippl, M., Zukauskaite, E., Healy, A.: Shaping smart specialization: the role of placespecific factors in advanced, intermediate and less-developed European regions. Reg. Stud., $1-13(2019)$

10. Asheim, B.T.: Smart specialisation, innovation policy and regional innovation systems: what about new path development in less innovative regions? Innov. Eur. J. Soc. Sci. Res. 32(1), 8-25 (2019)

11. Balland, P.A., Boschma, R., Crespo, J., Rigby, D.L.: Smart specialization policy in the European Union: relatedness, knowledge complexity and regional diversification. Reg. Stud. 53(9), 1252-1268 (2019)

12. European Commission: Regional Innovation Scoreboard 2019. Publications Office of the European Union, Luxembourg (2019)

13. Eurostat, Regional GDP https://ec.europa.eu/eurostat/news/themes-in-the-spotlight/regionalgdp. Accessed 04 Jan 2020

14. S3 Platform, Calabria. https://s3platform.jrc.ec.europa.eu/regions/ITF6/tags/ITF6. Accessed 03 Jan 2020 
15. European Commission, What is Horizon 2020? https://ec.europa.eu/programmes/ horizon2020/en/what-horizon-2020. Accessed 15 Jan 2020

16. EU open Data portal, CORDIS-EU research projects under Horizon 2020 (2014-2020). https://data.europa.eu/euodp/en/data/dataset/cordisH2020projects. Accessed 04 Jan 2020

17. European Commission. Study on Network Analysis of the 7th Framework Programme Participation. Publications Office of the European Union, Luxembourg (2019)

18. Brandes, U., Robins, G., McCranie, A., Wasserman, S.: What is network science? Netw. Sci. 1(1), 1-15 (2013)

19. Freeman, L.C., Roeder, D., Mulholland, R.R.: Centrality in social networks: II. Experimental results. Soc. Netw. 2(2), 119-141 (1979)

20. CORDA data dictionary, H2020 standard definition. https://data.europa.eu/euodp/en/data/ dataset/cordisH2020projects. Accessed 04 Jan 2020

21. Advancing Place-Based Regional Innovation Policies. In: González-López, M., Asheim, B. T. (eds.) Regions and Innovation Policies in Europe; Learning from the Margins. Cheltenham: Edward Elgar (forthcoming)

Open Access This chapter is licensed under the terms of the Creative Commons Attribution 4.0 International License (http://creativecommons.org/licenses/by/4.0/), which permits use, sharing, adaptation, distribution and reproduction in any medium or format, as long as you give appropriate credit to the original author(s) and the source, provide a link to the Creative Commons license and indicate if changes were made.

The images or other third party material in this chapter are included in the chapter's Creative Commons license, unless indicated otherwise in a credit line to the material. If material is not included in the chapter's Creative Commons license and your intended use is not permitted by statutory regulation or exceeds the permitted use, you will need to obtain permission directly from the copyright holder.

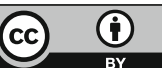

